\title{
Colorectal cancer
}

\author{
Anne B Ballinger, Clive Anggiansah
}

Homerton University Hospital NHS Foundation Trust, London E9 6SR Correspondence to: A B Ballinger anne.ballinger@homerton.nhs.uk

BMJ 2007;335:715-8 doi:10.1136/bmj.39321.527384.BE
Colorectal cancer is common, the presenting symptoms are non-specific, and the stage of disease at diagnosis is closely related to survival. In this review we discuss disease presentation, criteria for urgent referral of patients to specialist care, and recent developments in the implementation of national screening programmes, which aim to reduce mortality from this common disease. Many general practitioners will also refer patients with suspected colorectal cancer "direct to test" and this review covers the various modalities for investigation of patients with colorectal symptoms.

\section{Sources and selection criteria}

We searched PubMed for recent papers using the keywords "colorectal cancer", "screening", "investigation", and "incidence". We also searched the Cochrane Database of Systematic Reviews using the search terms "colorectal cancer" and "inflammatory bowel disease". In addition we used our personal reference archive.

\section{How common is colorectal cancer?}

In the Western world colorectal cancer is the second most common cancer in women after breast cancer and the third most common in men after lung and prostate cancer. ${ }^{12}$ Rates vary largely worldwide, being lowest in Africa and Asia and highest in Europe, North America, and Australasia. In the United Kingdom the lifetime incidence of colorectal cancer in people at average risk is $5 \%$ and the age standardised incidence rate is 44.3 per 100000 population. $^{3}$

\section{How does colorectal cancer develop?}

In most cases colorectal cancers arise from dysplastic adenomatous polyps. A multistep process involves the inactivation of a variety of genes that suppress tumours and repair DNA and the simultaneous activation of oncogenes. This confers a selective growth advantage to the colonic epithelial cell and drives the transformation from normal epithelium to adenomatous polyp to invasive colorectal cancer. ${ }^{4}$ Germline (hereditable) mutations underlie the well described inherited colon cancer syndromes whereas sporadic cancers arise from a stepwise accumulation of somatic genetic mutations. A single germline mutation in the APC tumour suppressor gene is responsible for the dominantly inherited syndrome, familial adenomatous polyposis coli. It is characterised by the development of hundreds to thousands of adenomatous polyps in the colon and development of colorectal cancer and other cancers in the third and fourth decade of life. Clinical expression of the disease is seen when the inherited mutation of one APC allele is followed by a "second hit" mutation or deletion of the second allele.

\section{Who is at greatest risk of colorectal cancer?}

Increasing age is the greatest risk factor for sporadic colorectal cancer: $99 \%$ of cases occur in people aged more than 40 and $85 \%$ in those aged more than 60 (fig 1). In Europe the incidence of colorectal cancer is gradually increasing, in part due to the ageing of the population but also due to an increase in the age specific incidence, suggesting that lifestyle or environmental factors, or both, contribute. The much higher incidence of colorectal cancer in more affluent countries compared with less developed countries is also thought to be related to lifestyle factors such as obesity and consumption of processed meat, and an inverse relation with physical activity and consumption of fruit and vegetables.

Next to age, family history is the most common risk factor for colorectal cancer. Familial adenomatous polyposis and hereditary non-polyposis colorectal cancer are the most common of the familial cancer syndromes, but together these two syndromes account for fewer than $5 \%$ of cases. About $10-20 \%$ of patients describe a family history of colorectal cancer, but the pattern of inheritance and clinical features are not consistent with one of these well characterised syndromes (table 1)..$^{5}$

\section{What are the symptoms of colorectal cancer?}

Abdominal pain, change in bowel habit, and rectal bleeding or anaemia are the commonest presenting symptoms of colorectal cancer but these symptoms also commonly occur in other gastrointestinal conditions. A change in bowel habit is a more common presenting symptom for left sided cancers caused by a progressive narrowing of the bowel lumen, with diarrhoea, a change in stool form, and eventually intestinal obstruction. About $10 \%$ of patients with iron deficiency anaemia have colorectal cancer, most commonly on the right side, and thus iron deficiency in men, and women who are not menstruating, is an indication for urgent referral and investigation. ${ }^{78}$

In 2005 the National Institute for Health and Clinical Excellence issued updated UK based guidelines that outlined signs and symptoms warranting 
Table 1 | Lifetime risk of dying from colorectal cancer according to family history, and recommendations for colonic screening in United Kingdom 56

\begin{tabular}{lcc} 
Risk group & $\begin{array}{c}\text { Lifetime risk of } \\
\text { colorectal cancer }\end{array}$ & $\begin{array}{c}\text { Refer for colonic } \\
\text { screening }\end{array}$ \\
Risk in general population & $1: 50$ & No \\
\hline One first degree relative affected (any age) & 2 -3-fold increased & No \\
\hline One first degree relative affected (age $<45$ years)* & 3 -4-fold increased & Yes \\
\hline Two first degree relatives affected (any age) & 3 -4-fold increased & Yes \\
\hline
\end{tabular}

*Initial colonoscopy is recommended between the ages of 35 and 40 years, or 10 years before the age of cancer diagnosis in the family member if this is earlier. American guidelines use a cut-off value of $₫ 60$ years.

urgent referral (within two weeks) for further specialist review or investigation of suspected colorectal cancer (table 2).

\section{How should suspected colorectal cancer be investigated? \\ Colonic imaging}

Table 3 summarises the advantages and disadvantages of the various investigations of the colon. ${ }^{9-14}$ All methods for examining the whole colon require full preparation of the bowel with oral laxatives, and the diagnostic yield of the examination depends on adequate preparation. Computed tomographic colonography (virtual colonoscopy) provides an endoluminal view of the colon similar to that of traditional colonoscopy. Technical improvements with this method (intravenous contrast material and oral faecal tagging agents) may allow stool and polyps to be differentiated and thus obviate the need for prior bowel preparation. The probability of colorectal cancer is low in patients with symptoms that suggest a lesion in the left colon (change in bowel habit or fresh rectal bleeding) but who do not have polyps or cancer visible at flexible sigmoidoscopy. Thus this may be an appropriate investigation in low risk patients - for example, fresh rectal bleeding only in patients aged less than 50 years - but otherwise the entire colon should be examined when colorectal cancer is suspected clinically.

Patient choice is an important factor in deciding on type of investigation. Prospective studies of patients who underwent two, or in some cases three, consecutive

Table 2 | Referral guidelines from the National Institute for Health and Clinical Excellence for suspected colorectal cancer, 2005

\section{Symptoms and signs}

Rectal bleeding with change in bowel habit to looser stools or increased frequency of defecation, or both, persistent for six weeks

Definite palpable right sided lower abdominal mass consistent with involvement of large bowel

Definite palpable rectal (not pelvic) mass

Rectal bleeding persistently without anal symptoms*

Change of bowel habit to looser stools or increased frequency of defecation, or both, without rectal bleeding, persistent for six weeks

Iron deficiency anaemia without obvious causes (haemoglobin level $<110 \mathrm{~g} / \mathrm{l}$ in men or $<100 \mathrm{~g} / \mathrm{l}$ in women who are not menstruating) $\ddagger$

*Include soreness, discomfort, itching, lumps, prolapse, and pain.

$\dagger 60$ years is considered maximum age threshold. Local cancer networks may elect to set lower thresholds (for example, 55 or 50 years).

$\ddagger B$ ritish Society of Gastroenterology recommends urgent referral and investigation for any level of iron deficiency anaemia. ${ }^{8}$

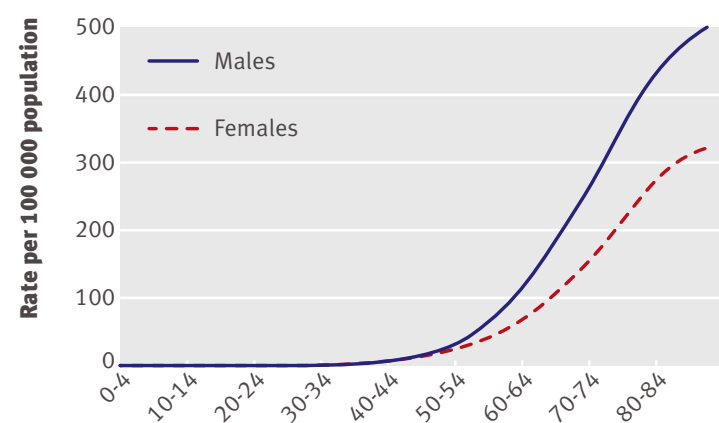

Age at diagnosis (years)

Fig 1 Age specific incidence of colorectal cancer in men and women. Adapted from Cancer Research UK (http://info. cancerresearchuk.org/cancerstats/types/bowel/incidence)

imaging tests showed that computed tomographic colonography and standard colonoscopy were equally acceptable, and both were preferable to double contrast barium enema. ${ }^{1516}$ Plain computed tomography of the abdomen is a useful investigation in patients with a large palpable abdominal mass of unclear colonic origin

\section{Frail and elderly patients}

Conventional colonic imaging tests may be difficult to carry out in elderly or frail patients because of immobility and poor tolerance to bowel preparation. Prospective studies with clinical outcome at 12-30 months have shown that in patients with symptoms plain computed tomography of the abdomen with oral contrast (but without bowel preparation) has a sensitivity for detection of colon cancer of 88-94\%. ${ }^{17}{ }^{18}$ Equivocal tests may need further investigation.

\section{Other tests}

Testing for faecal occult blood and measurement of serum tumour markers such as carcinoembryonic antigen are not useful in the investigation of suspected colorectal cancer. Faecal occult blood testing is an effective means of population screening in asymptomatic people but it is too insensitive to guide the investigation of patients with colonic symptoms. Similarly, tumour markers lack sensitivity and specificity but may be useful in the follow-up of treated patients. Wireless capsule endoscopy for imaging the colon is currently under development.

\section{How is colorectal cancer managed?}

Staging of the disease and complete visualisation of the colon are required once colorectal cancer is diagnosed, other than in the emergency setting. Liver and chest imaging, usually with computed tomography, is necessary to detect metastases, and a complete colonic assessment can detect synchronous cancers, present in $3-5 \%$ of patients. Endorectal ultrasonography or magnetic resonance imaging is also necessary to stage rectal cancer. Surgical resection for localised colorectal cancer offers the only curative possibility. Postoperative chemotherapy offers a survival benefit for patients after 
Table 3 | Comparison of current methods for examining the colon

\begin{tabular}{|c|c|c|c|c|c|}
\hline \multirow[b]{2}{*}{ Modality } & \multirow[b]{2}{*}{$\begin{array}{l}\text { Seda- } \\
\text { tion }\end{array}$} & \multirow{2}{*}{$\begin{array}{l}\text { Perforation } \\
\text { rate } \\
\text { (diagnostic) }\end{array}$} & \multirow{2}{*}{$\begin{array}{l}\text { Biopsy or } \\
\text { polypectomy, } \\
\text { or both }\end{array}$} & \multicolumn{2}{|c|}{ Sensitivity for detection (\%) } \\
\hline & & & & $\begin{array}{l}\text { Large polyps } \\
\quad(>10 \mathrm{~mm})\end{array}$ & Cancer \\
\hline \multicolumn{6}{|l|}{ Endoscopic: } \\
\hline $\begin{array}{l}\text { Standard (optical) } \\
\text { colonoscopy }\end{array}$ & Usually & $2: 1000^{\star}$ & Yes & 98 & 97 \\
\hline Flexible sigmoidoscopy & Rarely & $1: 10000^{*}$ & Yes & $\begin{array}{c}\text { Examines left } \\
\text { colon only }\end{array}$ & $\begin{array}{c}\text { Examines left } \\
\text { colon only }\end{array}$ \\
\hline \multicolumn{6}{|l|}{ Radiological: } \\
\hline $\begin{array}{l}\text { Double contrast barium } \\
\text { enema }\end{array}$ & No & $1: 10000$ & No & 48 & $83-94$ \\
\hline $\begin{array}{l}\text { Computed tomographic } \\
\text { (virtual) colonography }\end{array}$ & No & $5: 10000$ & No & $59-85$ & 97 \\
\hline
\end{tabular}

resection of stage II disease and selected patients with stage III disease. Preoperative chemoradiotherapy improves survival compared with surgery alone for rectal cancer. Palliative chemotherapy can alleviate symptoms, improve quality of life, and improve survival in patients with metastatic colorectal cancer. ${ }^{19}$ In some cases survival is improved by resection of liver and lung metastases.

\section{What is the prognosis of colorectal cancer?}

The outcome of colorectal cancer depends on the stage at diagnosis; about half of patients presenting with symptoms are at Dukes's stage C or D (table 4). ${ }^{2021}$ Five year survival rates are lower in the United Kingdom, Denmark, and eastern European countries compared with the European average of about $50 \%{ }^{22}$ Analysis of the EUROCARE data (European cancer registries study) suggests that lower survival in the United Kingdom results from later stage at presentation and diagnosis rather than inferior treatment for a similar stage. ${ }^{23}$

\section{Who should enter a screening programme? Family history \\ Moderate risk}

Healthy asymptomatic people with a family history of colorectal cancer should be considered for screening (table 1). ${ }^{56}$ Conventional colonoscopy remains the ideal investigation but computed tomographic colonography is used to examine the remaining colon when colonoscopy is incomplete-for example, as a result of technical difficulties preventing passage of the scope. The aim of colonic surveillance is to identify and remove adenomatous polyps thus preventing subsequent development into invasive cancer.

\begin{tabular}{|c|c|c|}
\hline $\begin{array}{l}\text { Dukes's stage modified } \\
\text { (equivalent TNM stage) }\end{array}$ & Description & 5 yearly survival rate $(\%)$ \\
\hline A (stage I) & Localised to mucosa and submucosa & 93 \\
\hline B (stage IIA and IIB) & $\begin{array}{l}\text { Extending into or through muscle layer } \\
\text { without lymph node involvement }\end{array}$ & $72-85$ \\
\hline C (stage IIIA-C) & Lymph node involvement & $44-83$ \\
\hline D (stage IV) & Distant metastases & 8 \\
\hline
\end{tabular}

High risk

People with one of the defined genetic family cancer syndromes - for example, familial adenomatous polyposis or hereditary non-polyposis colorectal cancerhave a high risk of colorectal cancer and should be referred to a local clinical genetics unit for possible formal counselling and mutation analysis of the respective gene. Hereditary non-polyposis colorectal cancer is the commonest of the family cancer syndromes and is caused by a DNA mismatch repair gene (that is, a gene that helps DNA to repair itself) mutation that predisposes patients to colorectal and also extra-colonic cancers (endometrial, ovarian, genitourinary, small bowel, and biliary tract).

\section{Inflammatory bowel disease}

Patients with longstanding total ulcerative colitis and Crohn's colitis are also at risk for colorectal cancer. National guidelines recommend that colonoscopic surveillance should begin after 8-10 years for pancolitis and 15-20 years for left sided disease. A recent Cochrane review did not find conclusive evidence that surveillance colonoscopy prolongs survival in these patients. Cancers are, however, likely to be detected at an earlier stage, with an associated better prognosis, and indirect evidence suggests that surveillance reduces death from colorectal cancer associated with irritable bowel disease. ${ }^{24}$

\section{What are the methods for screening populations for colorectal cancer?}

Population screening for colorectal cancer has been the subject of several recent high quality controlled clinical trials. The most widely investigated screening modality has been faecal occult blood testing based on the knowledge that cancer and polyps may bleed. A positive result is followed by imaging of the whole colon, usually with colonoscopy. Cancers detected by such screening are at an earlier stage (mostly Dukes's A and B) than

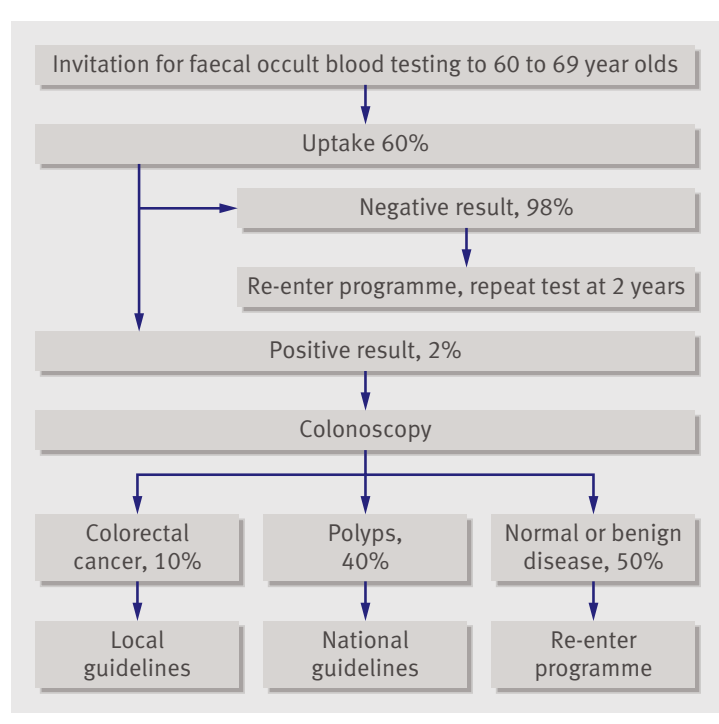

Fig 2 | Expected outcomes in bowel cancer screening programme $^{26}$ 


\section{Additional educational resources}

National Institute for Health and Clinical Excellence (www.nice.org.uk/guidance/ (SGCC)—Department of Health document for improving outcomes in colorectal cancer British Society of Gastroenterology (www.bsg.org.uk)—Clinical practice guidelines for a variety of gastrointestinal conditions

Cochrane Library (www.cochrane.org) — Independent systematic reviews of healthcare interventions to guide clinical decision making

Information for patients

NHS cancer screening programmes (www.cancerscreening.nhs.uk/bowel/index.html) -Contains information leaflets about the NHS bowel cancer screening programme

BBC (www.bbc.co.uk/health/conditions/cancer/typescancer_bowel.shtml)_

Information about bowel cancer, with a section on lifestyles that are associated with a reduced risk, and details of organisations that can provide medical and emotional help and support

Cancer Research UK (http://info.cancerresearchuk.org)—Colorectal cancer and other cancers covered in detail symptomatic cancers (table 4$) \cdot{ }^{20}$ Meta-analysis of four randomised controlled trials has shown that screening using faecal occult blood testing reduced the risk of death from colorectal cancer by $25 \%$ of those screened. It is estimated that screening using faecal occult blood testing will avoid about 1 in 6 of deaths from colorectal cancer. ${ }^{25}$ Ongoing studies should prove if removal of polyps reduces the subsequent development of colorectal cancer. The National Health Service bowel cancer screening programme began in 2006 and will be phased in gradually over three years. Home testing kits for faecal occult blood testing are sent to people aged 60-69 years every two years and on request to those aged 70 or more. Patients with positive results are invited to undergo colonoscopy at their local designated screening centre (fig 2).

Other screening strategies include flexible sigmoidoscopy every five years with or without faecal occult blood testing, double contrast barium enema, or colonoscopy every 10 years. All of these methods, used in people from age 50 years, reduce mortality from colorectal cancer compared with no screening and the cost per life saved compares favourably with mammography for women aged more than 50 and treatment of moderate hypertension. No single strategy has, however, proved to be the most effective or cost effective for screening. ${ }^{27}$ American guidelines recommend that people at average risk should be offered one of these screening strategies from age 50 and thus at a younger age than in the United Kingdom but at a higher cost per life saved. ${ }^{5}$

\section{SUMMARY POINTS}

The lifetime risk of developing colorectal cancer is about $5 \%$

Increasing age and a family history of colorectal cancer are the greatest risk factors for the disease

Patients presenting with suspicious symptoms and signs should be referred and investigated urgently in a specialised unit

Colonoscopy and computed tomographic colonography are of equal sensitivity for detection of colorectal cancer

Colonoscopy allows biopsy of suspicious lesions and removal of polyps

Population screening by testing for faecal occult blood has begun in the United Kingdom
Contributors: $\mathrm{ABB}$ and $\mathrm{CA}$ participated in the literature search and writing of the article. $A B B$ is the guarantor

Competing interests: None declared.

Provenance and peer review: Commissioned and externally peer reviewed.

1 Boyle P, Ferlay J, Cancer incidence and mortality in Europe 2004. Ann Oncol 2005;16:481-8.

2 Office for National Statistics. Cancer statistics registrations: registrations of cancer diagnosed in 2004, England. www.statistics.gov.

3 Quinn M, Babb P, Brock A, Kirby L, Jones J. Cancer trends in England and Wales 1950-1999. Vol SMPS No 66, 2001. www.statistics.gov.

4 Arnold CN, Goel A, Blum HE, Boland CR. Molecular pathogenesis of colorectal cancer. Cancer 2005;104:2035-47

5 Winawer S, Fletcher R, Rex D, Bond J, Burt R, Ferrucci J, et al. Colorectal cancer screening and surveillance: clinical guidelines and rationale-update based on new evidence. Gastroenterology 2003;124:544-60.

6 Dunlop MG. Guidance on large bowel surveillance for people with two first degree relatives with colorectal cancer or one first degree relative diagnosed with colorectal cancer under 45 years. Gut 2002;51(suppl V):17-20.

7 Rockey DC, Cello JP. Evaluation of the gastrointestinal tract in patients with iron-deficiency anemia. N Engl J Med 1993;329:1691-5.

8 Goddard AF, James MW, McIntyre AS, Scott BB. Guidelines for the management of iron deficiency anaemia. London: British Society of Gastroenterology, 2005. www.bsg.org.uk.

9 Rockey RC, Paulson E, Niedzwiecki D, Davis W, Bosworth HB, Sanders L, et al. Analysis of air contrast barium enema, computed tomographic colonography, and colonoscopy: prospective comparison. Lancet 2005;365:305-11.

10 Mulhall BP, Veerappan GR, Jackson JL. Meta-analysis: computed tomographic colonography. Ann Intern Med 2005;142:635-50.

11 Van Rijn IC, Reitsma JB, Stoker J, Bossuyt PM, van Deventer SJ, Dekker E. Polyp miss rate determined by tandem colonoscopy: a systematic review. Am J Gastroenterol 2006;101:343-50.

12 McDonald S, Lyall P, Israel L, Coates R, Frizelle F. Why barium enemas fail to identify colorectal cancers. Aust N Z J Surg 2001;71:627-8.

13 Rex DK, Rahmani EY, Haseman JH, Lemmel GT, Kaster S, Buckley JS Relative sensitivity of colonoscopy and barium enema for detection of colorectal cancer in clinical practice. Gastroenterology 1997:112:17-23.

14 Leslie A, Virjee JP. Detection of colorectal carcinoma on double contrast barium enema when double reporting is routinely performed: an audit of current practice. Clin Radiol 2002;57:184-7.

15 Gluecker TM, Johnson CD, Harmsen WS, Offord KP, Harris AM, Wilson LA, et al. Colorectal cancer screening with CT colonography, colonoscopy, and double-contrast barium enema examination: prospective assessment of patient perceptions and preferences. Radiology 2003;227:378-84

16 Bosworth HB, Rockey DC, Paulson EK, Niedzwiecki D, Davis W, Sanders LL, et al. Prospective comparison of patient experience with colon imaging tests. Am / Med 2006;119:791-9.

17 Ganeshan A, Upponi S, Uberoi R, D'Costa H, Picking C, Bungay H. Minimal-preparation CT colon in detection of colonic cancer, the Oxford experience. Age Ageing 2007;36:48-52.

18 Kealey SM, Dodd ID, MacEneaney PM, Gibney RG, Malone DE. Minimal preparation computed tomography instead of barium enema/colonoscopy for suspected colon cancer in frail elderly patients: an outcome analysis study. Clin Radiol 2004;59:44-52.

19 Gill S, Blackstock AW, Goldberg RM. Colorectal cancer. Mayo Clin Proc 2007;82:114-29.

20 O'Connell JB, Maggard MA, Ko CY. Colon cancer survival rates with the new American Joint Committee on Cancer sixth edition staging. J Natl Cancer Inst 2004;96:1420-5.

21 Niv Y, Lev-El M, Fraser G, Abuksis G, Tamir A. Protective effect of faecal occult blood test screening for colorectal cancer: worse prognosis for screening refusers. Gut 2002;50:33-7.

22 Coleman MP, Gatta G, Verdecchia A, Estève J, Sant M, Storm H, et al. EUROCARE-3 summary: cancer survival in Europe at the end of the 20th century. Ann Oncol 2003;14:v128-46.

23 Gatta G, Capocaccia R, Sant M, Bell CMJ, Coebergh JWW, Damhuis RAM, et al. Understanding variations in survival for colorectal cancer in Europe: a EUROCARE high resolution study. Gut 2000;47:533-8.

24 Collins PD, Mpofu C, Watson AJ, Rhodes JM. Strategies for detecting colon cancer and/or dysplasia in patients with inflammatory bowel disease. Cochrane Database Syst Rev 2006;(2):CD000279.

25 Hewitson P, Glasziou P, Irwig L, Towler B, Watson E. Screening for colorectal cancer using the faecal occult blood test, Hemoccult. Cochrane Database Syst Rev 2007;(1):CD001216.

26 NHS bowel cancer screening programme. www.cancerscreening.nhs. uk/bowel/index.html.

27 Pignone M, Saha S, Hoerger T, Mandelblatt J. Cost-effectiveness analyses of colorectal cancer screening. Ann Intern Med 2002;137:96-104 